\title{
Screening Tools for Kindergarten Children
}

\author{
https://doi.org/10.3991/ijes.v5i4.8013 \\ Georgia Kokkalia, Athanasios Drigas $\left({ }^{\bowtie}\right)$ \\ N.C.S.R. 'Demokritos', Agia Paraskevi, Athens, Greece \\ dr@iit.demokritos.gr \\ Alexandra Economou, Petros Roussos \\ University of Athens, Athens, Greece
}

\begin{abstract}
The current paper review gives a brief and representative description of some of the most used screening tools for kindergarten education. The significant role that early education plays in every child's academic life is underlined by the importance of tools that give his learning profiles. Therefore many researchers note that screening tools paly a notable role for the kindergarten teachers, the family and of course for the child in order to offer the appropriate intervention program, the proper support and draw the most suitable teaching method for the child and the class. Thus, the research team of this paper gives the description of some screening tools that are used by kindergarten teachers and specialist's worldwide-with focus in Greek kindergarten- scoping to underlie strengths and weaknesses of preschoolers. Finally, it is thought worthwhile to say that the screening tools that are presented are used with the traditional way while some of them with the support of new technology.
\end{abstract}

Keywords - Greek educational system, kindergarten education, screening tools

\section{Introduction}

Technology is truly everywhere [1] and its widespread adoption in various applications influences almost every aspect of modern life. Amongst them, the society's prospect of the ICT (Information and Communication Technologies) role in education has also changed. Today children seem to be more involved in the learning process, because they have the advantage of the technology special means to support their assignments [2]. ICT in education can make teaching and learning more effective and efficient [3], as they do not involve just learning about technology, but learning with technology. The early identification of speech, language and behavioral disorders or delays is a crucial first step in the effective prevention of developmental and socioemotional problems [4] and children's early cognitive and language development has bearing on later development and readiness for learning and social competence [5]. In the field of language learning and assessment, computerized applications are limited, particularly for the Greek language while most diagnosticians use qualitative means of assessment based on their personal experience [6]. On the other hand, computer 
capabilities, if used appropriately and responsibly, can expand the resources and improve the efficiency of language learning and assessment [7].

Moreover, screening measures offer a brief snap- shot of child development. One of the first types of screening tools was found in Spartan society where an assessment similar to an Apgar test was used with newborns. If children failed the test, their lives were terminated. Fortunately, we have progressed and now use better methods to get children the help and support they need. Today we use developmental screening measures in an early detection system aimed at locating children with difficulties who are in need of early intervention or early childhood special education services. Screening measures can also be used in a tracking program, or developmental surveillance, to monitor children who are at risk for developing a disability. However, at this time, empirically validated screening practices, procedures, and tools to identify children who require specialized supports and services are limited. Thus, it is important to have an evidence base for modern methods of screening young children for analyzing their strengths and their weaknesses [8].

However, the most important benefit of early detection is the fact that it does not entail the pupil's school failure, as is the case with the classical diagnostic process, which requires the student to have been taught systematic reading and writing in order to initiate the identification process. On the other hand, in the case of early detection of difficulties experts are based on well-documented assessment indicators that are easy to be used and evaluated at the pre-school age [9].

In the light of the above statements, educators know that children entering kindergarten vary in their early experiences, skills, knowledge, language, culture and family background. Social-emotional development and health and physical well being require as much emphasis as cognitive development, since all areas of development are connected. Communities, families and early childhood providers all play a role in providing nurturing, safe environments that promote healthy development for each individual child. As a result, the aim of this study is to examine and present the screening procedures and available tools that are used in the literature for early childhood age focusing also, on the case of Greek kindergarteners. Standardized and nonstandardized evaluation activities are discussed briefly, highlighting on traditional and computer-based screening tests that are used often by educators and specialists.

\section{Boehm test}

The Boehm Test of Basic Concepts-3 (Boehm-3) and Boehm Test of Basic Concepts-3 Preschool (Boehm-3 Preschool) were designed to assess young children's understanding of basic relational concepts important for language and cognitive development, as well as success in school across all learning areas [10]. The major purpose of each level of the test is to identify gaps in learning to guide instruction and intervention during a child's schooling toward success. Classroom teachers, speechlanguage pathologists, school psychologists, and other special education professionals can all use and benefit from this knowledge about the students they teach. The Boehm-3 covers 50 concepts that appear in print materials, reading and mathematics 
curricula, and professionals' verbal instructions for kindergarten through secondgrade students. The test is group administered but can be individually administered as a criterion referenced measure to older children who have special needs. Two parallel forms of the test include English and Spanish norms for fall and spring. Assessing the whole class early in the fall offers professionals a quick picture of the students' proficiency in concept understanding for instructional planning. In the spring, use of the alternate form of the test makes assessment of progress easy and accurate. Validity was established by review of mathematics and reading curricula and concepts used by teachers when giving instructions. The Boehm-3 Preschool is an individually administered test that covers 26 concepts at each of two age levels ( 3 years 0 months to 3 years 11 months; 4 years 0 months to 5 years 11 months) and is also appropriate, as a criterion-referenced measure for older children who have special needs. Each concept is assessed twice to identify concepts that are emerging, concepts that the child knows, or concepts that need development. English and Spanish norms are presented at 6-month age bands. The child responds to verbal instructions by pointing to one of four options on a picture [11]. Finally, the Boehm-3 can be used to identify students who may be at risk for a learning difficulty and may need referral for additional testing, to identify students in the classroom who know most concepts, but are having difficulty understanding a few key concepts that are embedded in instruction, for preand post-testing to determine progress as a result of instruction or intervention and finally as part of a battery of tests to assess students' language comprehension skills [12].

\section{GraphoGame}

GraphoGame (in Finnish, Ekapeli) is a digital, Web-based learning environment designed to support children's reading acquisition [13].The development of the GraphoGame at the University of Jyväskylä, Finland, is based on the findings of the Jyväskylä Longitudinal Study of Dyslexia. This research suggests that future reading problems often stem from difficulties in the perceptual differentiation of the manifestations of phonemes that are acoustically close and the consequent problems in learning the connections between letters and sounds. GraphoGame provides intensive training in letter-sound connections that have been shown to help children overcome these difficulties from kindergarten age.

In the basic letter-sound connection task of GraphoGame, the player hears a sound while a number of letters (target and distracters) appear on the screen. The child is expected to select the letter corresponding to the spoken sound. The game provides immediate feedback: Correct answers are acknowledged; if an incorrect answer was selected, the correct alternative is highlighted before the next trial is presented. To develop reading skills in a language with a transparent writing system (such as Finnish), the game begins with connections between single sounds and letters. Once the child has mastered this skill, the game advances to developing the connections between spoken and written syllables and words. Because of the adaptive level of difficulty, the game remains optimally challenging regardless of the child's skill level at 
each stage of his/her playing and, hence, supports a child's sense of competence. The GraphoGame interface is simple and easy to use, and most children are able to play the game without assistance from adults. With parental consent, the players' usage data are stored on the GraphoGame Web server. Parents and teachers who want to observe how their students or children are performing in the game, as well as by researchers who are interested in studying the learning processes of the players can use these data. The GraphoGame method was designed to facilitate children learning to connect written language segments with the corresponding speech sounds. Initially, the game was developed for children learning to read in the Finnish language and, more specifically, for those who showed early signs of reading difficulty at the end of kindergarten, just months before entering the first grade. This tool is used as a screening and support tool for learning as is not a replacement of teaching but rather provides preventive help [14].

\section{Bracken Basic Concept Scale (BBCS)}

The Bracken Basic Concept Scale is used to evaluate the concept development of children aged between 2.6 and 8 . The scale has 11 subtests, which cover the recognition of color, letter, number/counting, comparison, shape, direction/position, social/emotional concepts, size, texture and material, quantity and time. Each child starts BBCS from the first item of each of the first five subtests and continues with these sub-tests until s/he fails consecutively in three items. The score obtained by children on these five subtests is used to estimate the initial level of success that the child will display in each of the remaining sub-tests. The starting items of the tests that range between 6 to 11 are lettered from A to K. The child gets one point for every correct answer on each of the subtests. Every correct answer is marked as " 1 " and every wrong answer as "0". The BBCS was designed to assess children's (ages 2 years, 0 months to 8 years, 6 months) receptive understanding of important concepts within each of 11 distinct conceptual categories. Each conceptual category was researched to identify the scope of basic concepts embedded within the category, the sequence with which children learn these categorical concepts, and effective means by which to remediate conceptual deficiencies [15].

The original 258 BBCS concepts were presented in test items as black-and-white line drawings embedded within 11 distinct domains: Colors, Letters, Numbers/Counting, Sizes, Shapes, Comparisons, Direction/Position, Self-/SocialAwareness, Texture/Material, Quantity, and Time/Sequence. Despite the fact that the assessment of concept development is not legislatively mandated, the BBCS has a practice and research niche among developmental, child clinical, and school psychologists, as well as with early childhood educators and speech and language pathologists. Since its original publication, researchers have used the BBCS in largescale assessment and intervention projects internationally. The test was revised and reformed once more in 2007 and expanded to two forms: a receptive measure akin to the original and revised BBCS, Bracken Basic Concept Scale: Third Edition- Recep- 
tive (BBCS:3-R; Bracken, 2007a), and an expressive measure, the Bracken Basic Concept Scale: Third Edition-Expressive [16].

\section{$5 \quad$ Alpha Test}

Alpha test - Screening test for school readiness [17] is a very short screening test for children 5-6 years that examines the learning and emotional readiness of a child for elementary school, so as to prevent school failure and serious social and mental disturbances. It is not an intelligence test and its evaluation is computer-based. The Alpha Test checks school readiness, hyperactivity / distraction and test behavior as a standard multi-subject test that evaluates the child's learning ability through two communication paths: Acoustics / Linguistics and Optical-perceptual. The first evaluates, the Verbal Skill, (e.g. the child's ability to handle speech and words) while the latter assesses the Practical Skill, (e.g. what the child can do with his / her hands).

As it is well known that learning ability is a complex function involving many individual competencies the test should include individual scales that will assess these many different abilities. All together determine the child's ability to join the school program successfully. A 'TEST comprises 7 individual scales, which Evaluate different learning and cognitive functions, namely: Critical ability, Linguistic analogies, Early Abstract Thinking, Visual-Kinetic Co-ordination, Optical Concept, Broad Mobility and Sequences.Each of the individual scales of school readiness is graded with a specific numeric index. From the statistical and cumulative processing of the individual specific numerical indices, a numerical set of units is expressed, which expresses the school's overall readiness for the child as a whole. All units correspond to a specific developmental cognitive age. The ability to evaluate the test on a scale but at the same time as a whole is important because it allows to identify areas of child development that require particular attention.

Moreover, the ability to evaluate the test on a scale but at the same time as a whole is important because it allows to identify areas of child development that require particular attention. A 'TEST is a screening test that provides high level information with significant predictive validity in terms of the child's future learning ability. Its biggest advantage is that it can be applied as a preventative - detection tool, easily, quickly, reliably in large child populations. The structure of the test offers the examiner the ability to evaluate the findings both overall and individually, on a scale, as depicted in the child's internal diagram. By granting TEST, the examiner can, within a short period of time, "detect" objective information about the child's developmental abilities and attempt a proposal for full developmental control where it is deemed necessary.

Finally, A 'TEST can also help educators to properly inform and advise parents to deal with difficulties with special handling or special treatment programs (speech therapy, occupational therapy, special treatment, etc.) [18]. 


\section{Test of Early Identification of Dyslexia}

The test of early identification of dyslexia helps educators and specialists to diagnose suspicions, signs and tendencies for subsequent dyslexia under specific agerelated conditions and appropriately structured subjects of the cognitive subject[19]. More specifically, the main principles followed in designing and implementing the test, and determined to a significant extent both its diagnostic and prognostic role, indicate that the test of Early identification of Dyslexia seeks to highlight those factors likely to be involved in an early stage of dyslexia in preschool age despite the fact we can not be confident about the type of dyslexia. An important element is that through this test educators may determine whether a child shows difficulties and peculiarities, offering him the appropriate support according to the areas he faces difficulties. Also, this test can be used to prevent labeling and formulating absolute and permanent characteristics, and to outline the areas where a dyslexic child may encounter difficulties in the preschool age. The themes that are included in the test were selected from a fairly large number of themes, evaluated and processed, through a process of piloting their content and form. Finally, eight items were selected, which their features are related to the main factors of dyslexia. The items that are examined through this test are the following eight (8) test subclasses:

Test 1. Image Recognition. Ten different picture cards are presented to the child and is asked to recognize the object-type illustrated.

Test 2. Painting. We present to the child three kinds of objects and we ask him to paint them.

Test 3. Copying geometric shapes. The child copies shapes that are given to him

Test 4. Visual distinction. The child is required to distinguish and identify specific geometric shapes.

Test 5. Laterality test. We investigate the level of the child's lateral structure through some specific activities that we call it to carry out.

Test 6. Name Script. We ask from the child to write or copy his name.

Test 7. Distinction of sounds. We call the child to repeat pairs of words that have sound similarities to each other.

Test 8. Optical Tolerance. We present the child with specific geometric shapes on specific cards and we call it to map the common features between these shapes.

Moreover, it is important to note that this test must be administrated by nursery teachers and teachers in order to observe the child's learning behavior, to highlight the importance of acquiring writing as the main form of communication and acquisition of new knowledge, to demonstrate the possibility of timely and valid diagnosis and proper re-education and finally offer the appropriate psycho-emotional support to children with dyslexic symptoms in preschool age. The delivery of the test by nursery teachers and teachers is also important because the educator will propose forms of individualized teaching and applications of special teaching programs in preschool age. In addition, by providing the test, the educator will be able to help the child more effectively to overcome the difficulties early in order to smoothly integrate into the normal classroom and school success. 
Finally, this test could be used also by specialists, pediatric psychologists, special pedagogues, doctors or researchers as an additional measuring and diagnostic tool in the forms of intervention and reinforcement they apply to children with specific developmental dyslexia syndrome. The Early identification of Dyslexia Test should be performed by someone who knows and strictly adheres to the instructions for giving it, so as not to create anxiety and insecurity from the subject, to understand the information requested so that the child to respond exactly to what is being asked, and not to distort the aim and content of the measuring tool. The test is given individually, with an average completion time of twenty minutes and without the intervention of third parties or the use of materials other than those provided by the test package [20].

\section{The Early Childhood Skills Assessment Scale}

The Early Childhood Skills Assessment Scale is a weighted screening process that can be used to identify children in high-risk groups for special educational needs, and assess their learning outcomes [21] It is also a useful guide to grouping children, based on their learning potential, if deemed necessary by the preschool teacher. The Scale provides a focused basis for assessing the linguistic, mathematical, social, motor skills of children as well as their learning autonomy skills. The individual profile that results from the assessment describes the potential and the difficulties of each child in the above development areas, which can be correlated with his performance in the classroom. In this way, it is possible to locate the cognitive areas in which each child presents difficulties or deficits and facilitates the individualized or group intervention for the benefit of the children and the learning process at this school level. Finally, educators with the traditional way can use the scale for kindergarten children [22].

\section{Work Sampling System}

The Work Sampling System is an instructional assessment that is used in preschool through third grade and is a criterion-referenced observational assessment with extensive research supporting reliability and validity. Its purpose is to document and assess children's skills, knowledge, behavior, and accomplishments across a wide variety of curriculum areas on multiple occasions in order to enhance teaching and learning [23]. The Work Sampling System consists of three complementary elements: 1) Developmental Guidelines that cover seven major curriculum areas: personal and social development; language and literacy; mathematical thinking; scientific thinking; social studies; the arts; and physical development, health and safety. 2) Developmental Checklists that are customized for each grade level and 3) Summary Reports which replace conventional report cards as a way of recording progress, communicating with parents, and meeting reporting requirements. Using information from the Developmental Checklists, you can complete a Summary Report three times a year. The Work Sampling System calls for ongoing assessment that is summarized three times per year. By reflecting classroom goals and objectives, it helps teachers monitor chil- 
dren's continuous progress and places children's work within a broad developmental perspective. Through documenting and evaluating individual performance of classroom-based tasks, Work Sampling strengthens student motivation, assists teachers in instructional decision making, and serves as an effective means for reporting children's progress to families, educators, and community. More specifically, this tool collects information on the child's work and compares it to grade-specific guidelines, identify what children are learning, what they are beginning to master, and what they still need to work on offering the teacher a useful instruction planning [24].

\section{Basc 3}

The Behavior Assessment System for Children (BASC) holds an exceptional track record for providing a complete picture of a child's behavior. School and clinical psychologists have depended on BASC for more than 20 years as it is a test that helps children thrive in their school and home environments with effective behavior assessment. [25]. BASC-3 provides the most comprehensive set of rating scales that are both important for IDEA and DSM-5 classifications offering also the most extensive view of adaptive and maladaptive behavior. This comprehensive set of rating scales and forms including the Teacher Rating Scales (TRS), Parent Rating Scales (PRS), Self-Report of Personality (SRP), Student Observation System (SOS), and Structured Developmental History (SDH) help educators to understand the behaviors and emotions of children and adolescents. More specifically, BASC-3 applies a triangulation method for gathering information by analyzing the child's behavior from three perspectives-Self, Teacher, and Parent_-giving as a result a more complete and balanced picture. The Teacher Rating Scales measure adaptive and problem behaviors in the preschool or school setting. Teachers or other qualified observers can complete forms at three age levels - preschool (ages 2 to 5), child (ages 6 to 11), and adolescent (ages 12 to 21 ) - in about 10-20 minutes. The forms describe specific behaviors that are rated on a four-point scale of frequency, ranging from "Never" to "Almost Always." The TRS contains 105-165 items. Validity and response set indexes used to help judge the quality of completed forms are also available. Furthermore, the Parent Rating Scales (PRS) measure both adaptive and problem behaviors in the community and home setting. Parents or caregivers can complete forms at three age levelspreschool (ages 2 to 5), child (ages 6 to 11), and adolescent (ages 12 to 21) - in about 10-20 minutes. The PRS contains 139-175 items and uses a four-choice response format. Last, the Self-Report of Personality (SRP) provides insight into a child's or adult's thoughts and feelings. Each form — child (ages 8 to 11), adolescent (ages 12 to 21 ), college (ages 18 to 25 ) - includes validity scales for helping judge the quality of completed forms. The SRP takes about 30 minutes to complete. The benefits of the test are many because it uses a multidimensional approach for conducting a comprehensive assessment as it has a strong base of theory and research while enhanced computer scoring and interpretation provide efficient, and extensive reports. Last but not least, the test provides normed based results on current population characteristics (United States) while offers the ability to understand the differentiates between hy- 
peractivity and attention problems that a child may has with one efficient instrument [26].

\section{Dial}

The DIAL-4 is an appropriate screening tool for children ages 2.6 years to 5.11 years. The tool is individually administered but is appropriate for use in environments where mass kindergarten screenings occur, taking approximately 25-35 minutes per child to administer. Each of five performance areas is scored on a behavior (psychological and social) rating scale. Behaviors are observed during the screening process to help determine if further assessment is needed and there are currently two versions in English and Spanish language. The tool offers comprehensive information in five performance areas [27].

- Motor - Gross Motor items include catching, jumping, hopping, and skipping. Fine Motor items include building with blocks, cutting, copying shapes and letters, and writing and finger-touching tasks.

- Language - Items include answering simple personal questions (name, age, and sex), articulation, naming (expressive) or identifying (receptive) objects and actions, plus phonemic awareness tasks such as rhyming.

- Concepts - Items include pointing to named body parts, naming or identifying colors, rote counting, counting blocks, identifying concepts in a triad of pictures, and sorting shapes. Also included is an item that assesses automatic naming of objects, a skill that is associated with potential learning disabilities.

- Self-help Development - Examining a child's development related to personal care skills such as dressing, eating, and grooming.

- Social Development - Examining a child's social skills with other children and parents - includes rule compliance, sharing, self-control, and empathy.

Lastly, the results from DIAL-4 assist parents in understanding their child's developmental readiness for kindergarten, as well as provide information to kindergarten teachers to use as they plan the types of experiential opportunities that are most appropriate for students in their classes [28].

\section{Conclusion}

Taking the above into consideration we may consider the importance and the significant role that screening tools play for kindergarten children. In this brief description we presented some of the most well known tools that are used in Greek educational system and worldwide. Research has demonstrated that high quality early childhood education and care can have lasting, positive outcomes both for children from disadvantaged backgrounds and children from non-disadvantaged backgrounds [29]. The wide range of environments throughout the world in which young children grow and learn creates challenging questions for everyone concerned with providing 
high-quality screening tools in order to offer the appropriate intervention program to them. As it was noticed from the research they're not many screening tools for children that attend kindergarten and thus not enough support for the kindergarten teachers and for kindergarten specialist teachers that assess children in this age. However, the majority of specialists today support that early detection and prognosis of learning difficulties appears to contribute to helping to cope with their consequences [30]. Early detection is usually associated with pre-emption and consequent primary-level intervention to address any difficulties. In more detail, early detection generally refers to a screening assessment that may also be carried out in the school context by a specially trained teacher or nurse in order to achieve overall better school performance and increase the sense of positive academic experience [31]. In the light of the above arguments we have the belief that there is need of the development of more screening tools that may help kindergarten children and teachers. Moreover, in the Greek educational system there is enough room and space of designing screening tools for kindergarten children offering as a result support not only to the children but also at the same time to the teachers who feel the emerge need of this type of reinforcement.

\section{References}

[1] Gillard, S., Bailey, D., and Nolan, E., Ten reasons for IT educators to be early adopters of IT innovations. Journal of Information Technology Education, 7, 2008, 39-45. https://doi.org/10.28945/176

[2] Toki, E. I., and Pange, J, E-learning activities for articulation in speech language therapy and learning for preschool children, Procedia-Social and Behavioral Sciences, 2(2), 2010, 4274-4278. https://doi.org/10.1016/j.sbspro.2010.03.678

[3] Toki, E. I., and Pange, J., A Comparative Study of Two Learning Methods: Collaborative Learning Versus Nearest Neighbor Learning, EISTA 2006 Proceedings, 2006, 20-23.

[4] Toki, E. I., and Pange, J., Traditional and computer-based evaluation of preschoolers' oral language in Greek-A review of the literature, Sino-US English Teaching, 9(1), 2012, 840845.

[5] Carscadden, J., Corsiatto, P., Ericson, L., Illchuk, R., Esopenko, C., Sterner, E., and Oddie, S. D., A Pilot Study to Evaluate a New Early Screening Instrument for Speech and Language Delays, Revue canadienne d'orthophonie et d'audiologie 34(2), 2010, 87-92.

[6] Protopapas, A.,and Skaloumbakas, C., Traditional and computer-based screening and diagnosis of reading disabilities in Greek. Journal of Learning Disabilities, 40(1), 2007, 15 36. https://doi.org/10.1177/00222194070400010201

[7] Biswal, B. B., Mennes, M., Zuo, X. N., Gohel, S., Kelly, C., Smith, S. M., and Dogonowski, A. M., Toward discovery science of human brain function. Proceedings of the National Academy of Sciences, 107(10), 2010, 4734-4739. https://doi.org/10.1073/pnas. 0911855107

[8] Buysse, V., and Wesley, P. W., Evidence-Based Practice in the Early Childhood Field, ZERO TO THREE, 2010,812-836.

[9] Protopapas, A., Mouzaki, A., Sideridis, G. D., Kotsolakou, A., and Simos, P. G., The role of vocabulary in the context of the simple view of reading, Reading \& Writing Quarterly, 29(2), 2013, 168-202. https://doi.org/10.1080/10573569.2013.758569

[10] Boehm, A. E.,Boehm test of basic concepts (New York: Psychological corporation.1971) 
[11] Spector, C. C., The Boehm Test of Basic Concepts: Exploring the test results for cognitive deficits, Journal of Learning Disabilities, 12(8), 1979, 564-567. https://doi.org/10.1177/ $\underline{002221947901200813}$

[12] McDermott, P. A., and Beitman, B. S., Standardization of a scale for the study of children's learning styles: Structure, stability, and criterion validity, Psychology in the Schools, 21(1), 1984, 5-14. https://doi.org/10.1002/1520-6807(198401)21:1<5::AID-PITS23102 10102>3.0.CO;2-B

[13] Lyytinen, H., Erskine, J., Kujala, J., Ojanen, E., and Richardson, U., In search of a science-based application: A learning tool for reading acquisition. Scandinavian journal of psychology, 50(6), 2009,668-675. https://doi.org/10.1111/j.1467-9450.2009.00791.x

[14] Richardson, U.,and Lyytinen, H., The GraphoGame method: The theoretical and methodological background of the technology-enhanced learning environment for learning to read, Human Technology, 10(1) 2014,182-201. https://doi.org/10.17011/ht/urn.201405281859

[15] Bracken, B. A., Ten psychometric reasons why similar tests produce dissimilar results. Journal of School Psychology, 26(2), 1998,155-166. https://doi.org/10.1016/00224405(88)90017-9

[16] Panter, J. E., and Bracken, B. A.,Validity of the Bracken School Readiness Assessment for predicting first grade readiness, Psychology in the Schools, 46(5),2009, 397-409. https://doi.org/10.1002/pits.20385

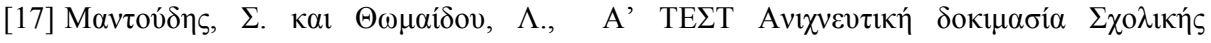

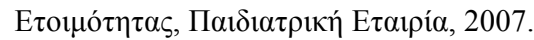

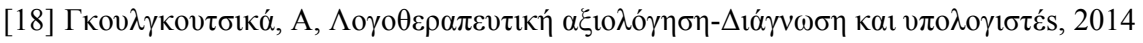

[19] Zakopoulou, V., and Stavrou, L., Test of early identification of dyslexia. The Dyslexia Online Journal, 1, 2002.

[20] Zakopoulou, V., Anagnostopoulou, A., Christodoulides, P., Stavrou, L., Sarri, I., Mavreas, V., and Tzoufi, M., An interpretative model of early indicators of specific developmental dyslexia in preschool age: A comparative presentation of three studies in Greece. Research in developmental disabilities, 32(6), 2011, 3003-3016. https://doi.org/10.1016/j.ridd. 2011.03.021

[21] Ralli, A. M. and Maridaki Kassotaki, A., Rating scale for the assesment of preschool children (In Greek), 2011.

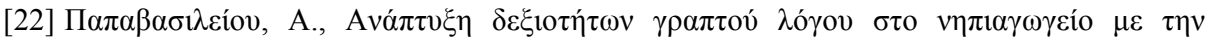
$\alpha \xi 10 \pi \circ i ́ \eta \sigma \eta \tau \omega \nu$ TПЕ, 2016.

[23] Meisels, S. J., Liaw, F. R., Dorfman, A., and Nelson, R. F., The Work Sampling System: Reliability and validity of a performance assessment for young children. Early Childhood Research Quarterly, 10(3), 1995, 277-296. https://doi.org/10.1016/0885-2006(95)90008-X

[24] Meisels, S. J., Performance assessment in early childhood education: The work sampling system (ERIC Clearinghouse, 1995).

[25] Merenda, P. F., BASC: Behavior Assessment System for Children. Measurement and Evaluation in Counseling and Development , 1996.

[26] Reynolds, C. R., and Kamphaus, R. W., BASC-3 Behavioral and Emotional Screening System manual, 2015

[27] Mardell, C., \& Goldenberg, D., DIAL-4: Developmental Indicators for the Assessment of Learning. (Pearson Clinical Assessment, 2014).

[28] Augustyniak, K. M., Cook-Cottone, C. P., and Calabrese, N., The predictive validity of the Phelps kindergarten readiness scale, Psychology in the Schools, 41(5), 2004, 509-516. https://doi.org/10.1002/pits.10180 
[29] Campbell, F. A., Ramey, C. T., Pungello, E., Sparling, J., and Miller-Johnson, S., Early childhood education: Young adult outcomes from the Abecedarian Project. Applied developmental science, 6(1), 2002, 42-57. https://doi.org/10.1207/S1532480XADS0601 05

Hatzichristou, C., Polychroni, F., and Georgouleas, G, School psychology in Greece. The handbook of international school psychology, 2007, 135-146. https://doi.org/10.4135/

9781412976138.n14

[30] Protopapas, A., Simos, P. G., Sideridis, G. D., and Mouzaki, A., The components of the simple view of reading: A confirmatory factor analysis, Reading Psychology, 33(3), 2010, 217-240. https://doi.org/10.1080/02702711.2010.507626

\section{Authors}

Athanasios Drigas is a Senior Researcher at N.C.S.R. Demokritos. He is the Coordinator of Telecoms Lab and founder of Net Media Lab since 1996. From 1985 to 1999 he was the Operational manager of the Greek Academic network. He has been the Coordinator of Several International Projects, in the fields of ICTs, and e-services (e-learning, e-psychology, e-government, e-inclusion, e-culture etc). He has published more than 200 articles, 7 books, 25 educational CD-ROMs and several patents. He has been a member of several International committees for the design and coordination of Network and ICT activities and of international conferences and journals. (email: dr@iit.demokritos.gr).

Alexandra Economou is an assistant professor at the University of Athens in the department of Psychology. She teaches undergraduate and postgraduate neuropsychology and experimental psychology courses at the University of Athens in the Department of Psychology while her interests focus on cognitive and biological psychology. Dr. Economou is also vice-president of the Greek Aphasia Association. (Email: aoikono@psych.uoa.gr)

Georgia Kokkalia (MSc in Specific Learning Difficulties) is a Special Education Teaching Professional and Phd Candidate in University of Athens. She has participated in various research projects regarding the use of Information and Communication Technologies (ICTs) in Special Education and in Kindergarten (E- mail: gioulina@hotmail.com).

Petros Roussos is an assistant professor at the University of Athens in the department of Psychology. Since 1994 he has taught cognitive psychology, research methods and statistics in psychology at the University of Crete (Greece), the University of the Aegean (Greece), the University of Athens and many other colleges and higher education institutions. He has served as adjunct research fellow of the Hellenic Pedagogical Institute (1998-2000), as Psychology Department Chair at the University of Indianapolis Athens Campus (2000-2004) and as Researcher at the Unit of Analysis and Documentation at the Greek Ministry of Employment and Social Protection (2004-2005). He is also a graduate member of the British Psychological Society, member of the Hellenic Psychological Society, and General Secretary of the Hellenic Cognitive Science Society (E-mail: roussosp@psych.uoa.gr).

Article submitted 13 November 2017. Published as resubmitted by the authors 17 December 2018. 